\title{
ANALISIS TERMODINAMIKA DAN EXERGI PADA PEMBANGKIT LISTRIK TENAGA PANAS BUMI SISTEM DOUBLE FLASH YANG MENGGUNAKAN INTERSTAGE HEATING
}

\author{
FAISAL NUR HAKIM, CUKUP MULYANA* , FERRY FAIZAL, CAMELLIA PANATARANI \\ Departemen Fisika Fakultas MIPA Universitas Padjadjaran, \\ Jl. Raya Bandung-Sumedang Km 21,Jatinangor 45363 \\ *email : cukup.mulyana@phys.unpad.ac.id
}

\begin{abstract}
Abstrak. Interstage heating merupakan suatu konsep pengembangan yang dilakukan pada pembangkit listrik sistem double flash, pada paper ini dilakukan analisis termodinamika terhadap model pemangkit double flash yang menggunakan interstage heating (Superheating, Reheating dan Mixture-heating) dengan parameter tinjauan adalah daya output dan exergi. Analisi termodinamika khususnya daya output dilakukan dengan meninjau pembangkit secara keseluruhan, sedangkan analisis exergi difokuskan pada bagian heat exchanger yang digunakan untuk interstage heating. Pada penelitian ini dilakukan variasi temperatur reservoir $\left(180^{\circ} \mathrm{C}-220^{\circ} \mathrm{C}\right)$ dengan temperatur dead steate adalah $25^{\circ} \mathrm{C}$. Hasil dari penelitian ini memperlihatkan bahwa interstage heating dapat menjadi konsep yang konstruktif atau destruktif, konstruktif untuk tipe reheating dan mixture heating karena mengalami kenaikan daya output dan exergi, destruktif untuk tipe superheating karena mengalami penurunan daya output dan exergi, konstruktif dan destruktif ini dititik beratkan penyebabnya pada proses transfer panas yang terjadi di heat exchanger, secara keseluruhan tipe interstage heating terbaik adalah tipe mixture heating dengan kenaikan daya output rata-rata sebesar $7.6 \%$ dan exergi rata-rata sebesar $1.1 \%$ saat dibandingkan dengan sistem double flash.
\end{abstract}

Kata kunci: double flash, interstage heating, daya, exergi

\begin{abstract}
Interstage heating is development concept on double flash system, in this paper, double flash system using interstage heating (Superheating, Reheating and Mixtureheating) are analyzed with the review parameters are output power and exergy. Thermodynamic, especially output power, is analyzed by reviewing the whole power plant, while exergy is focused on the heat exchanger which is used for interstage heating. In his research, reservoir temperature are performed by variation in range $\left(180^{\circ} \mathrm{C}-220^{\circ} \mathrm{C}\right)$ with dead state temperature is $25^{\circ} \mathrm{C}$. The results of this study show that interstage heating can be a constructive or destructive concept, constructive for the type of reheating and mixture heating, because it has increased output power and exergy, destructive for the superheating type due to decreased output and exergy power, these advantages and disadvantages are emphasized by the cause in the heat transfer process that occurs in the heat exchanger, overall the best type of interstage heating is the mixture heating with an average output power increases of $7.6 \%$ and an average exergy of $1.1 \%$ when compared to the double flash system.
\end{abstract}

Keywords: double flash, interstage heating, output power, exergy

\section{Pendahuluan}

Indonesia memiliki potensi panas bumi yang sangat besar di dunia karena letak geografisnya yang berada di Ring of Fire [1]. Sumber daya energi panas bumi di Indonesia diperkirakan mencapai sekitar 28,5 Giga Watt electrical (GWe) yang 
terdiri dari resources 11,073 MW dan reserves 17,453 MW [2]. Sistem panas bumi di Indonesia umumnya merupakan sistem hidrothermal yang mempunyai suhu tinggi $\left(>225^{\circ} \mathrm{C}\right)$, hanya beberapa diantaranya yang mempunyai suhu sedang $(150$ $225^{\circ} \mathrm{C}$ ) [3]. Sebagian besar reservoir panas bumi yang terletak di Indonesia merupakan sistem dominasi air (water-dominated) [4], sehingga jenis pembangkit listrik yang umum digunakan di Indonesia adalah pembangkit listrik tenaga panas bumi dengan sistem flashing.

Pembangkit listrik tenaga panas bumi dengan sistem single flash merupakan jenis yang paling umum digunakan, sistem single flash biasanya dianggap sebagai alternatif paling sederhana dan ekonomis [5] untuk sumber daya panas bumi yang tersedia di Indonesia. Namun, ketersediaan energi panas bumi yang tinggi dan pemanfaatan energi panas bumi yang masih relatif rendah menunjukan rasio pemanfaatan energi yang masih belum optimal yaitu sekitar 5\% [1]. Optimalisasi merupakan suatu strategi yang dapat menjadi alternatif permasalahan rasio yang relatif kecil, optimalisasi PLTP dapat dilakukan dengan cara meningkatkan sistem yang telah ada yaitu single flash menjadi double flash. Sistem ini merupakan pengembangan dari sistem single flash yang kelebihannnya adalah dapat memproduksi sekitar 15-25\% daya yang lebih besar dengan kondisi fluida panas yang sama [6]. Kemajuan teknologi telah mendorong para peneliti untuk lebih mengoptimalkan sistem double flash ini, system ini dapat di optimalkan kembali dengan menggunakan interstage heating. Interstage heating merupakan suatu konsep yang menambahkan heat exchanger kedalam sistem pembangkit sehingga dapat memanfaatkan panas internal pembangkit seefisien mungkin dengan tujuan untuk menaikan performa pembagkit. Konsep ini telah dibuat oleh Andrey Raymond Sarr (2015) [7] yang terinspirasi dari Mathieu-Potvin (2013) [8] and DiPippo (2013) [9]. Parameter yang sering menjadi pertimbangan ketika ingin merealisasikan suatu model pembangkit adalah daya output dan exergi, pada penelitian ini dilakukan analisis terhadap desain interstage heating dengan menggunakan analisis termodinamika secara keseluruhan dan analisis exergi yang difokuskan pada heat exchanger karena komponen utama pada interstage heating ini adalah heat exchanger, sehingga dapat terlihat performa setiap tipe pembangkit dan diperjelas fenomenanya dengan analisis exergi.

Pembangkit listrik sistem double-flash merupakan suatu pembangkit yang melakukan proses flashing dua kali untuk mendapatkan performa optimum, biasanya system pembangkit ini mempunyai temperatur minimal yaitu sekitar $180^{\circ} \mathrm{C}$. Supaya system pembangkit lebih optimum dan tidak terlalu banyak panas yang terbuang maka system double flash ini dapat ditingkatkan kembali dengan menggunakan interstage heating. Interstage heating akan menambahkan heat exchanger kedalam sistem double flash agar terjadi pertukaran panas antara satu titik dengan titik lainnya sehingga terjadi pertukaran panas yang dapat menaikan daya pembangkit.

System pembangkit double flash merupakan suatu pembangkit yang memiliki dua buah separator dan dua buah turbin, Hal ini dapat dilihat dari Gambar 1.a, perbedaan antara turbin atau separator pertama dan kedua adalah tingkat tekanannya. Tingkat tekanan komponen terbagi menjadi dua yaitu high pressure dan low pressure, pada saat brine keluar dari reservoir, brine tersebut memiliki tekanan yang relatif besar sehingga akan melalui separator pertama (high pressure separator) dan turbin pertama (high pressure turbin). Brine fasa cair keluaran separator pertama akan mengalami proses flashing kedua di throttle valve dan mengalami penurunan tekanan sehingga tekanannya sudah turun, brine akan masuk ke separator kedua 
(low pressure separator) untuk mengalami pemisahan fasa, brine fasa uap keluaran separator kedua akan bercampur dengan brine fasa cair keluaran turbin pertama di mixer untuk selanjutnya masuk ke turbin kedua (low pressure turbin) untuk menghasilkan daya output. Brine yang telah dimanfaatkan akan didinginkan di kondensor dan masuk kembali kedalam reservoir.

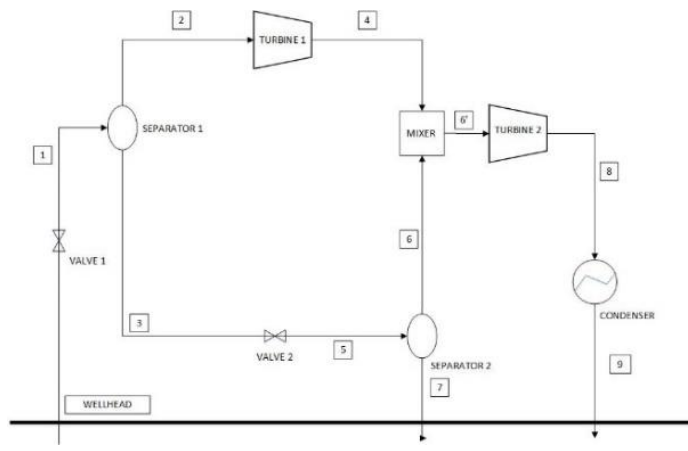

(a)

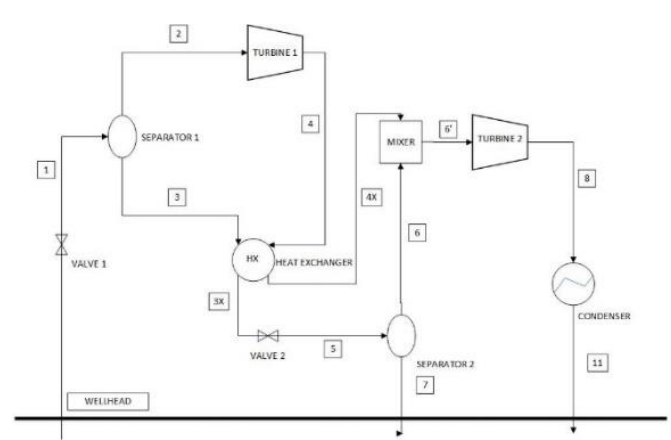

(c)

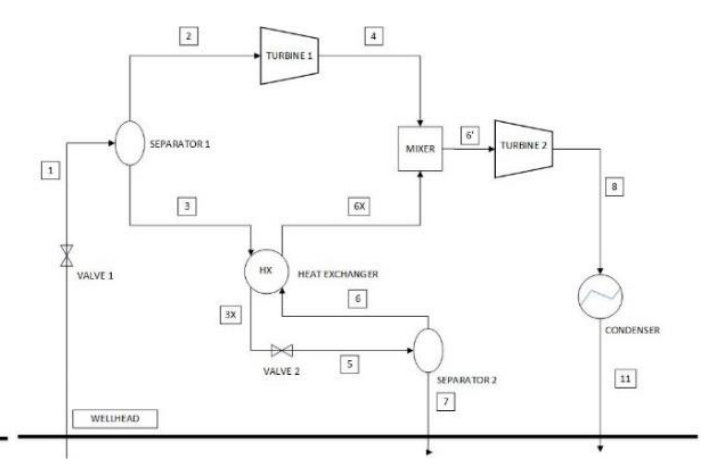

(b)

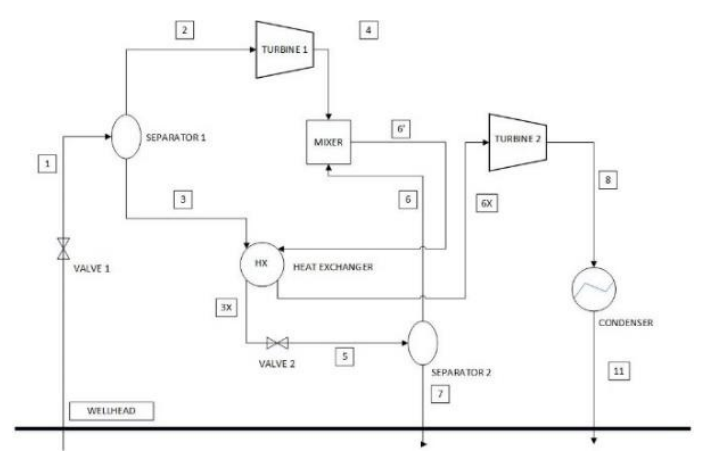

(d)

Gambar 1. Skema pembangkit (a) sistem double flash (b) tipe Superheating (c) tipe Reheating (d) tipe Mixture-heating

Pengembangan sistem double flash menggunakan interstage heating yang pertama adalah type superheating. Pada Gambar 1.b dapat terlihat bahwa pada design ini ditambahkan sebuah heat exchanger yang digunakan untuk mentransfer fluida fasa liquid dari keluaran separator pertama ke fluida fasa uap keluran separator kedua . Proses transfer ini dilakukan dari titik yang mempunyai entalpi relatif besar ke titik fluida yang mempunyai entalpi relatif rendah dan membutuhkan entralpi lebih besar untuk dapat digunakan memutar turbin kedua menjadi lebih maksimal. Efek yang terjadi akibat transfer panas ini adalah brine cair keluaran separator pertama akan mengalami penurunan pada entalphinya karena ditransferkan sebagian ke brine fasa uap keluaran separator kedua, sehingga fluida yang masuk ke separator kedua yang merupakan hasil flashing di throttle valve memilki fasa uap yang lebih kecil dari keaadan normal atau ketika tidak digunakan konsep interstage heating.

Pengembangan sistem pembangkit yang kedua adalah Reheating. Konsep kerja type ini relatif sama dengan type superheating, perbedaannya terletak dipenerima panas, jika pada superheating, panas yang didapat dari brine cair keluaran separator pertama digunakan untuk memanaskan brine uap keluaran separator kedua, pada jenis ini brine cair keluaran separator pertama digunakan untuk memanaskan brine 
keluaran turbin pertama yang terlihat seperti Gambar 1.c. Brine keluaran turbin pertama dan brine uap keluaran separator kedua akan bercampur di mixer yang nantinya digunakan untuk memutarkan turbin kedua. Fenomena atau efek yang terjadi pada system ini adalah brine keluaran turbin pertama akan mengalami kenaikan entalphi dan kualitas uap, konsep dapat dikatakan sebagai konsep yang lebih baik dari konsep superheating, hal ini dikarenakan penempatan fluida yang menjadi penerima panasnya adalah brine keluaran turbin pertama, titik dimana kualitas uapnya relatif kecil, sehingga saat titik ini mendapatkan transfer panas, kualitas uap naik dan hal ini merupakan hal yang bagus, karena untuk memutarkan turbin dibutuhkan kualitas uap yang tinggi agar menghasilkan output lebih besar.

Pengembangan sistem yang ketiga adalah Mixture-heating. Design mixture heating ini dapat dikatakan merupakan pencampuran antara superheating dan reheating. Konsep ini dapat dilihat pada Gambar 1.d merupakan konsep yang menggunakan heat exchanger untuk memanaskan fluida yang menuju turbin kedua yaitu fluida campuran dari fluida cair keluaran turbin pertama dan fluida uap keluaran separator kedua. Pencampuran ini berakibat pada parameter mass flow dari fluida campuran yang semakin meningkat. Dengan terjadinya percampuran ini panas yang diterima menjadi semakin besar, karena semakin besar mass flow pada titik tersebut, transfer panas yang diterima akan semakin besar. Keuntungan dengan adanya peningkatan mass flow dan entalphi pada fluida campuran tersebut dimanfaatkan untuk memutarkan turbin kedua untuk menghasilkan daya output yang lebih besar. Efek negative yang terjadi pada konsep ini adalah Karena panas yang ditransferkan relatif besar maka terjadi penurunan entalpi yang relatif besar pula, yang menyebabkan kualitas uap pada separator kedua lebih kecil sehingga steam keluaran separator kedua lebih kecil.

\section{Metode Penelitian}

Metoda yang digunakan dalam penelitian ini adalah analisis dengan melakukan perbandingan 3 model interstage heating dari sudut pandang termodinamika dan exergi. Variasi parameter yang dilakukan pada penelitian ini adalah temperatur sumur reservoir yang dilakukan dalam rentan $180-220^{\circ} \mathrm{C}$. Parameter yang digunakan untuk penelitian ini adalah $\dot{m}_{\text {reservoir }}=2300 \mathrm{~kg} / \mathrm{h}, \mathrm{T}_{\mathrm{s} 2}=120^{\circ} \mathrm{C}, \eta_{h x}=$ $80 \%$, Kualitas uap reservoir $=20 \%, \mathrm{~T}_{\mathrm{o}}=25^{\circ} \mathrm{C}$, dan $\mathrm{T}_{\text {condensor }}=60^{\circ} \mathrm{C}$. Parameter tinjauan utama pada penelitian ini adalah daya output dan exergi.

Pembangkit listrik panas bumi sistem double flash menggunakan interstage heating mengalami beberapa proses disetiap komponennya, mulai dari separator, throttle valve, turbin, heat exchanger, mixer dan condenser. Pada saat brine memasuki separator maka brine akan mengalami proses pemisahan fasa antara fasa uap dengan fasa cair, pemisahan pada bagian separator itu tergantung dari kualitas uap yang dimiliki brine sesaat sebelum memasuki separator. Brine fasa uap yang telah memasuki separator akan diteruskan ke komponen selanjutnya yaitu turbin, sehingga brine fasa uap ini dapat memutar turbin dan menghasilkan daya keluaran. Berbeda dengan fasa uap, fasa cair keluaran separator akan memasuki bagian komponen throttle valve, didalamnya brine akan mengalami proses penurunan tekanan agar kualitas uap dapat bertambah, proses ini dinamakan flashing. Pada saat proses ini kualitas uap dapat diketahui dengan menggunakan persamaan.

$$
x=\frac{h_{f g}-h_{f}}{h_{g}-h_{f}}
$$


$\mathrm{x}$ adalah kualitas uap brine, $\mathrm{h}_{\mathrm{fg}}$ adalah entalpi dari brine yang keluar dengan fasa campuran liquid dan gas, $h_{g}$ merupakan entalpi brine pada saat fasa gas, dan $h_{f}$ merupakan entalpi brine pada saat keadaan liquid. Pada saat brine sudah mengalami proses flashing, maka brine sudah menjadi fasa campuran liquid dan gas, brine ini akan disalurkan kembali kedalam separator untuk dilakukan proses pemisahan agar fasa uap yang terkandung dapat dimanfaatkan kembali untuk memutarkan turbin. separator pada sistem double flash ada dua, yaitu Seperator pertama yang digunakan untuk brine yang memiliki tekanan yang relatif tinggi (High Pressure Separator) dan separator kedua yang memiliki tekanan yang relatif rendah (Low Pressure Separator). Ketika system menambahkan konsep interstage heating pada pembangkit double flash maka akan digunakan penambahan komponen berupa heat exchanger yang digunakan untuk mentranferkan panas dari satu titik ke titik lain. Proses transfer panas ini diperhitungkan dengan menggunakan rumus:

$$
\begin{aligned}
& \dot{m}_{s}\left(h_{s, i}-h_{s, o}\right)=\dot{m}_{t}\left(h_{t, i}-h_{t, o}\right) \\
& \eta_{h x}=\frac{h_{t, i}-h_{t, o}}{h_{s, i}-h_{s, o}}
\end{aligned}
$$

Dengan $\dot{m}_{s}$ adalah mass flow bagian shell, $h_{s, i}$ adalah entalphi brine yang masukan pada bagian shell, $h_{s, o}$ adalah entalphi brine yang keluar pada bagian shell, $\dot{m}_{t}$ adalah mass flow bagian tube, $h_{t, i}$ adalah entalphi brine yang masukan pada bagian tube, $h_{t, o}$ adalah entalphi brine yang keluar pada bagian tube, dan $\eta_{h x}$ adalah efesiensi heat exchanger. Pada model ini transfer panas yang dilakukan bersumber dari brine fasa cair keluaran separator pertama untuk memanaskan brine fasa uap keluaran separator kedua (Superheating), brine fasa campuran keluaran turbin pertama (Reheating), dan brine campuran keluaran separator kedua dengan keluaran turbin pertama (Mixture-heating). Hasil keluaran heat exchanger tentunya memiliki brine yang lebih besar kalornya karena mendapatkan transfer dari titik lain, brine ini dimanfaatkan untuk memutarkan turbin sehingga menghasilkan daya output, Nilai dari daya output dapat diketahui dengan menggunakan persamaan:

$$
\dot{W}=\dot{m}\left(h_{i}-h_{0}\right)
$$

Dengan $\dot{W}$ adalah daya output, $\dot{m}$ adalah mass flow, $h_{i}$ adalah entalphi brine yang masuk kedalam turbin, dan $h_{0}$ adalah entalphi yang keluar dari tubin. Pada saat proses ini brine yang masuk kedalam turbin akan mengalami penurunan entalphi karena telah dimanfaatkan untuk memutar turbin, setelah brine selesai dimanfaatkan maka brine akan di injeksikan kembali kedalam bumi, untuk itu maka sebelumnya brine harus mengalami penkondisian dan pendinginan melalui condenser sehingga brine bisa berubah kembali menjadi fasa cair dan dapat dikembalikan kedalam reservoir.

Energi dan Exergi adalah parameter-parameter yang berasal dari hukum termodinamika satu dan hukum termodinamika dua [10], Energi bersifat kekal dan tidak dapat dimusnahkan. Berbeda dengan energi, exergi bersifat tidak kekal yang disebakan oleh sifat ireversibelitas dari proses. Exergi adalah potensi kerja maksimum yang dapat dilakukan saat system mencapai kesetimbangan dengan lingkungannya [11]. Perhitungan exergi dapat dimanfaatkan untuk mengidentifikasi terjadinya disipasi exergi dan timbulnya kerugian. Hal ini memberikan perhatian atau peringatan pada aspek sistem operasi yang dapat 
memberikan kemungkinan yang lebih besar terhadap perbaikan sistem [6]. Exergi dapat dihitung dengan menggunakan rumus:

$$
\begin{aligned}
& \dot{E}_{1,2}=\dot{m}\left(\left(h_{1}-h_{2}\right)-T_{o}\left(s_{1}-s_{2}\right)\right) \\
& \dot{e}_{1,2}=\left(h_{1}-h_{2}\right)-T_{o}\left(s_{1}-s_{2}\right)
\end{aligned}
$$

$\dot{E}_{1,2}$ adalah Exergi untuk proses dua keadaan, $\dot{m}$ adalah mass flow, $h_{1}$ adalah entalphi untuk keadaan satu, $h_{2}$ adalah entalphi untuk keadaan kedua, $s_{1}$ adalah entropi untuk keadaan satu, $s_{2}$ adalah entropi untuk keadaan kedua, $\dot{e}_{1,2}$ adalah exergi spesifik untuk proses dua keadaan, dan $T_{o}$ adalah temperatur suhu lingkungan atau keadaan dead state.

\section{Hasil dan Pembahasan}

Perhitungan termodinamika setiap model dilakukan dengan parameter yang telah ditulis pada bagian metoda penelitian dengan temperatur reservoir untuk grafik pada gambar 2 dan 4 adalah $200^{\circ} \mathrm{C}$, dengan karakteristik tersebut tentunya setiap model menghasilkan ciri dan keunikannya masing-masing, komponen yang sangat mempengaruhi dalam perhitungan ini adalah heat exchanger yang digunakan untuk mendukung konsep interstage heating, setelah melakukan perhitungan maka didapatkan hasil seperti berikut.

Gambar 2.a memperlihatkan proses termodinamika disetiap titik, dimulai dari titik 1 merupakan titik komponen separator yang setelah dari komponen tersebut terbagi menjadi dua titik yaitu titik 2 yang merupakan brine fasa uap dan titik 3 yang merupakan brine fasa cair. Titik 2 akan diteruskan menuju turbin, sedangkan titik 3 akan disalurkan menuju throttle valve yang didalamnya mengalami proses flashing. Pada saat melakukan proses flashing brine akan mengalami penurunan temperatur dan kanaikan entropi untuk berubah menjadi fasa campuran yang memiliki nilai kualitas uap tertentu. Brine yang memiliki fasa campuran di titik 5 akan melalui proses pemisahan kembali pada separator kedua, brine fasa cair keluaran separator kedua akan dimasukan kembali ke dalam reservoir, sedangkan fasa uap keluaran separator kedua di titik 6 akan bercampur dengan brine fasa campuran titik 4 (kualitas uapnya tidak 100\%) keluaran turbin pertama di mixer yang menghasilkan brine fasa campuran pula. Karena brine di titik 6' ini memilki fasa campuran, hal ini mempengaruhi nilai entropi dari brine tersebut yang menyebabkan tidak maksimalnya brine saat dimanfaatkan untuk memutar turbin. Brine di titik 8 yang telah digunakan di turbin kedua akan didinginkan dikondesnser agar brine di titik 9 temperaturnya menurun dan fasanya menjadi cair untuk diinjeksikan kembali ke dalam reservoir.

Gambar 2.b merupakan gambar diagram T-s untuk double flash superheating, dari gambar tersebut dapat terlihat proses termodinamika yang hampir sama dengan proses termodinamika untuk double flash system, perbedaan yang dapat terlihat dari diagram $\mathrm{T}-\mathrm{s}$ ini adalah adanya titik tambahan yaitu titik $3 \mathrm{x}$ dan $6 \mathrm{x}$, adanya titik tambahan dipengaruhi oleh adanya penambahan komponen yaitu heat exchanger yang berfungsi sebagai implementasi konsep interstage heating, Heat exchanger disini berfungsi untuk mentranferkan kalor dari titik 3 ke titik 6, dari sana terlihat jelas bahwa setelah mengalami proses pertukaran panas,titik 3 menurun temperatur 
dan entropinya menjadi titik 3x, sedangkan titik 6 mengalami kenaikan temperatur dan entropi hingga titik 6x, kekurangan dari system superheating ini adalah titik dimana penerima panas dapat dikatakan kurang tepat, karena titik 6x ini akan bercampur terlebih dahulu dengan titik 4 dimana titik tersebut bukan brine yang memiliki kualitas uap 100\%, sehingga saat telah bercampur menjadi brine dititik 6' lalu digunakan untuk memutarkan turbin, brine tersebut tidak bekerja maksimal.

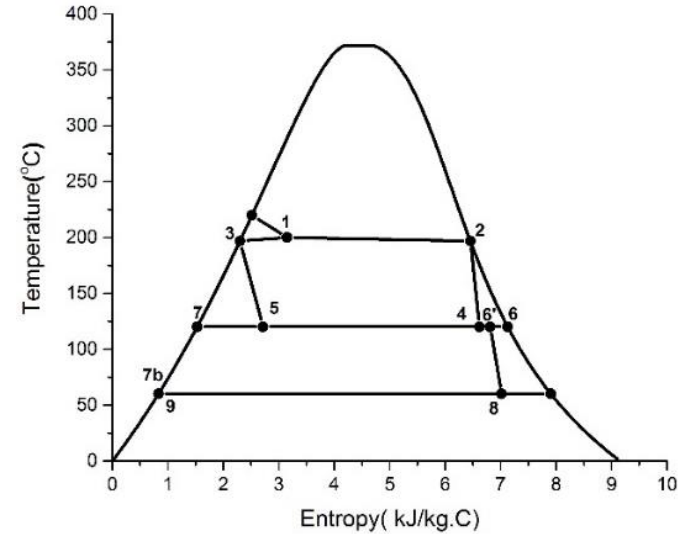

(a)

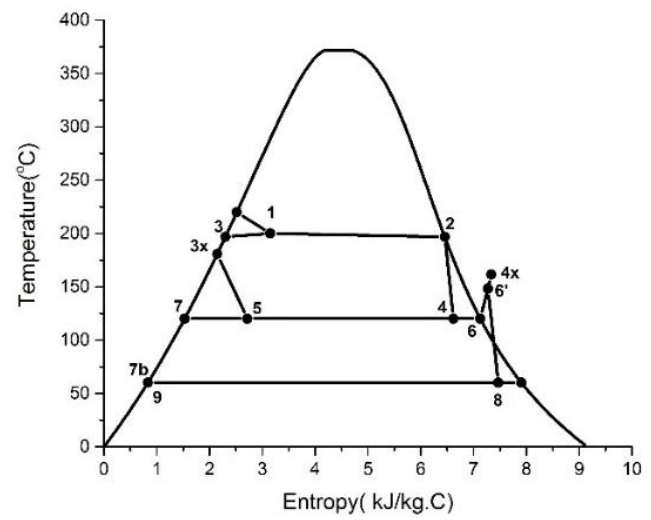

(c)

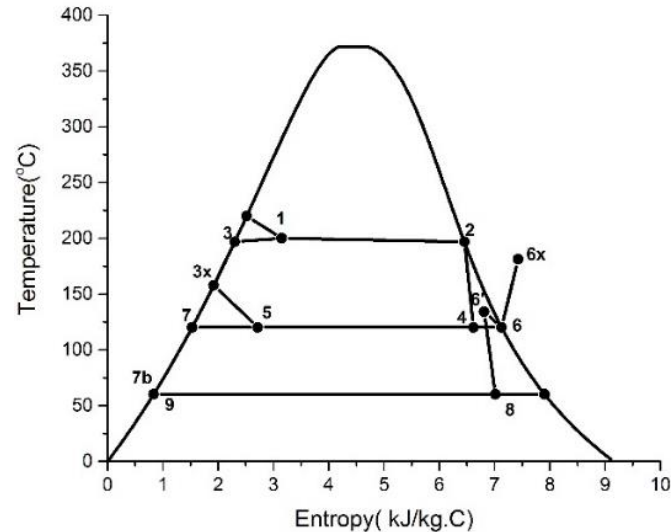

(b)

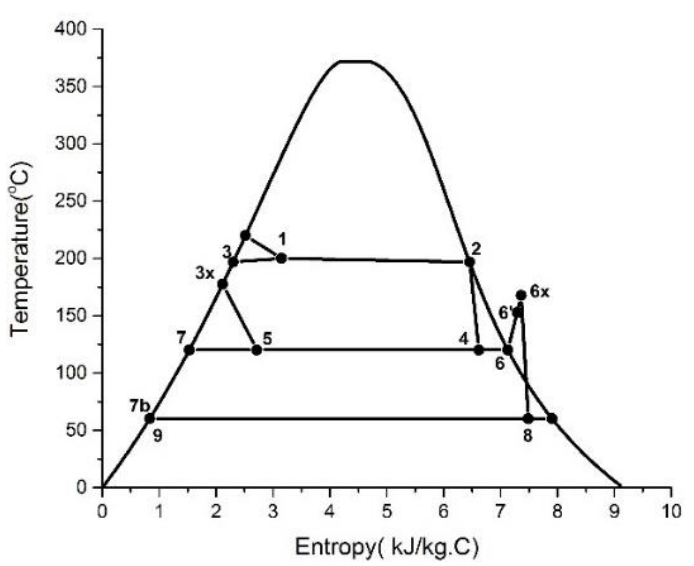

(d)

Gambar 2. Diagram T-s untuk (a) sistem double flash (b) tipe Superheating (c) tipe Reheating (d) tipe Mixture-heating

Gambar 2.c merupakan gambar diagram T-s untuk double flash reheating, secara sederhana proses termodinamika yang terjadi relatif sama dengan superheating, perbedaannya terletak pada proses pertukaran panas yang terjadi, jika pada superheating penerima panas adalah titik 6 , disini yang menjadi penerima panas adalah titik 4, jika dibandingkan dengan superheating, proses pertukaran panas tipe ini lebih efektif karena penurunan panas yang terjadi di titik 3 tidak terlalu besar dan peningkatan panas dititik $4 \mathrm{x}$ cukup tinggi, reheating system dapat dikatakan sebagai suatu konsep interstage heating yang berhasil, karena proses pertukaran terjadi antara titik yang mempunyai kalor relatif besar dengan titik yang membutuhkan kalor agar kualitas uap pada titik tersebut menjadi naik, efek yang sangat terasa dari proses ini adalah kualitas uap yang dihasilkan dari pencampuran 
brine di mixer bisa mencapai $100 \%$ karena mencampurkan brine yang keduanya memiliki kualitas uap 100\%, sehingga brine ini sangat efektif atau maksimal ketika digunakan untuk memutarkan turbin kedua.

Gambar 2.d merupakan grafik diagram T-s untuk double flash mixture-heating, jika dibanding kembali dengan superheating dan reheating, perbedaannya tentu terletak di penerima panas saat terjadi pertukaran panas di heat exchanger, konsep ini dapat dikatakan gabungan konsep superheating dan reheating karena memanaskan brine yang merupakan campuran titik 4 dan 6 yaitu titik 6x, dengan memilki mass flow yang lebih besar tentu saja titik 6x memiliki kemampuan menerima panas lebih besar disbanding superheating dan reheating, hal tersebut menyebabkan kualitas uap menjadi $100 \%$ serta panas yang diterima lebih besar sehingga pada saat brine digunakan untuk memutarkan turbin kedua menghasilkan daya output lebih besar.

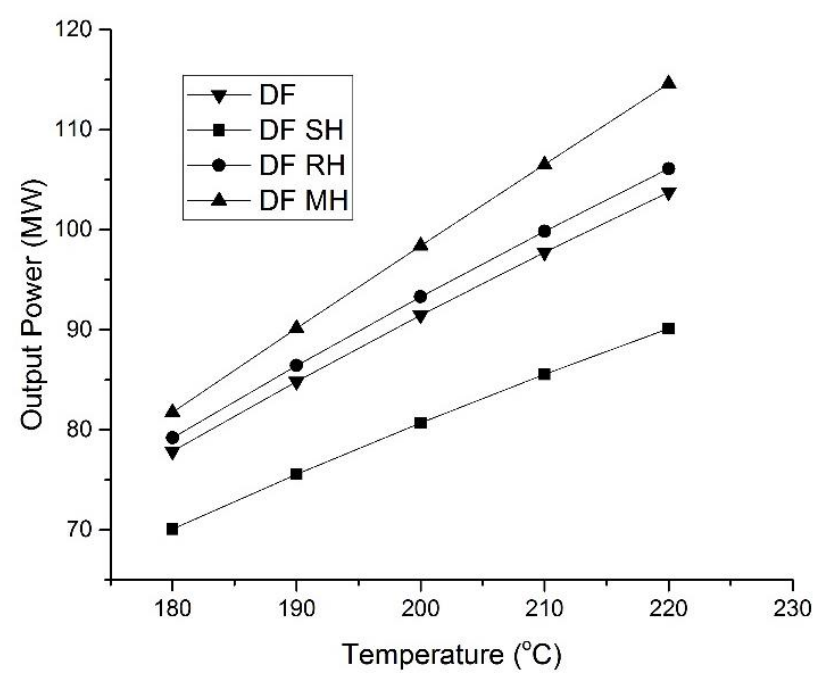

Gambar 3. Grafik perbandingan daya output terhadap temperatur reservoir

Gambar 3 merupakan grafik daya output yang dihasilkan berbanding dengan temperatur reservoir, jika dilihat dari grafik tersebut, semakin temperatur naik maka daya output juga naik, hal ini cukup rasional karena semakin besar temperatur reservoir maka tekanan yang dimiliki brine pada pembangkit akan semakin besar sehingga tenaga yang dibutuhkan untuk memutarkan turbin itu besar. Dilihat dari grafik tersebut mixture heating menjadi sistem yang memiliki daya yang paling besar, dengan kenaikan daya rata-rata 7.6\% jika dibandingkan dengan double flash, hal ini dapat terjadi karena terjadi proses pentransferan yang efektif dari titik yang memilki panas berlebih menuju titik yang membutuhkan panas untuk memutar turbin, diikuti dengan tipe reheating yang memilki daya output terbesar kedua dengan kenaikan daya rata-rata $2 \%$, hasil ini cukup terprediksi karena tipe ini dan tipe mixture heating lah yang mempunyai kualitas uap $100 \%$ untuk fluida yang memasuki turbin kedua, ditempat ketiga ditempati oleh tipe double flash tanpa interstage heating dan terakhir adalah tipe superheating, disini terjadi sebuah anomaly, karena seharusnya dengan menambahkan konsep interstage heating atau konsep yang memaksimalkan panas internal secara optimal, dapat menghasilkan daya yang lebih besar. Namun pada perhitungan / percobaan ini superheating ada dibawah double flash dengan penurunan daya rata-rata 11\%. Diperkirakan hal ini terjadi karena proses pertukaran panas pada heat exchanger tidak efektif. 


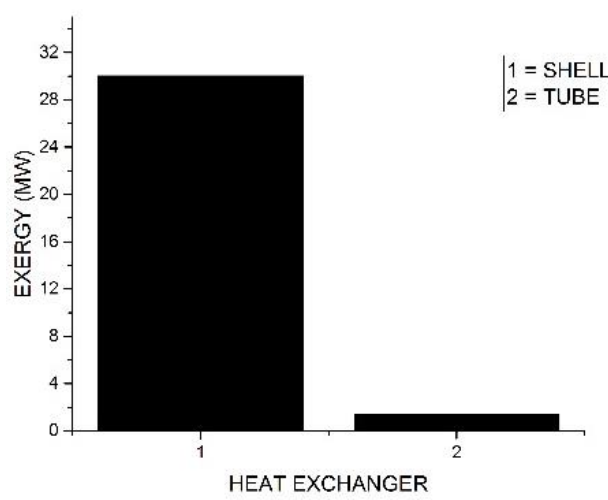

(a)

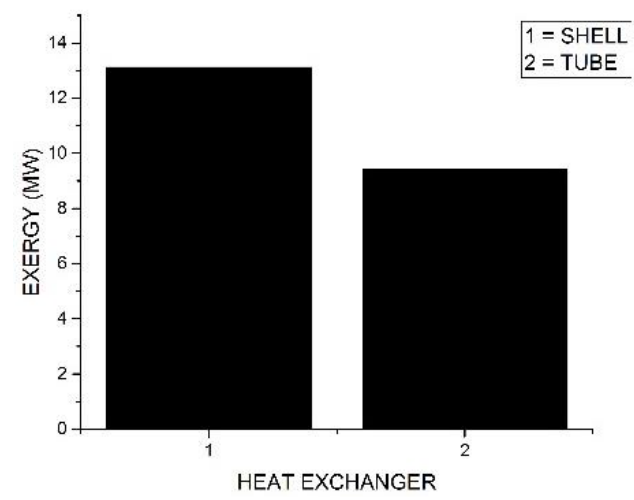

(b)

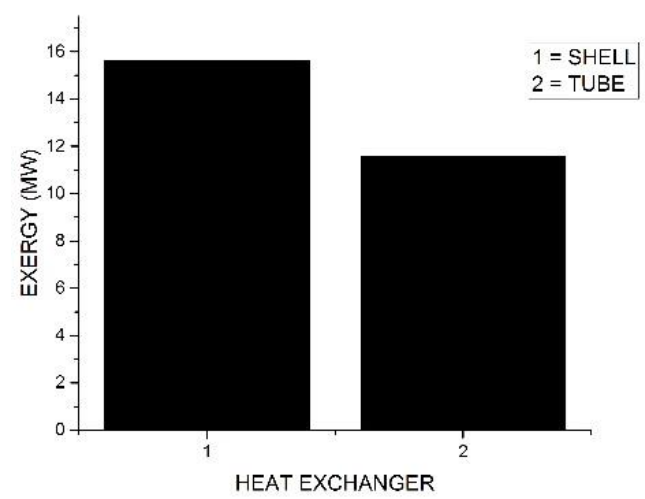

(c)

Gambar 4. Grafik exergi untuk heat exchanger pada sistem double flash (a) tipe Superheating (b) tipe Reheating (c) tipe Mixture-heating

Gambar 4.a merupakan grafik exergi untuk heat exchanger pada tipe superheating, heat exchanger berfungsi sebagai penukar atau pentranfer panas yang memiliki dua kutub / sisi yaitu kutub pentransfer panas dan kutub penerima panas. Untuk kutub pentranfer panas berada pada bagian shell dan untuk kutub penerima panas berada dibagian tube, dari grafik dapat terlihat bahwa selisih exergi antara pentranfer dan penerima panas sangan besar, hal ini akan sangat berpengaruh terhadap kinerja pembangkit, terutama panas yang diserap serta dibuang, jika kita memilki panas yang berlimpah untuk disalurkan tetapi penerima panas hanya dapat menerima sebagian kecil dari panas tersebut, maka panas yang terbuang saat terjadi pertukaran panas akan sangat besar, hal ini menyebabkan panas yang seharusnya digunakan untuk memutarkan turbin hilang sehingga daya ouput pembangkit akan semakin kecil.

Gambar 4.b merupakan grafik exergi untuk tipe reheating, dilihat dari grafik tersebut, penerima panas dan pentranfer panas memilki selisih yang relatif kecil, dengan proses pentranferan panas yang terbilang efektif akan berdampak pada daya output yang semakin besar, karena menerima panas tambahan berkat dari proses pertukaran panas pada heat exchanger yang menerapkan konsep interstage heating.

Gambar 4.c merupakan gambar exergi untuk tipe mixture heating, pada grafik tersebut tergambar bahwa besarnya nilai exergi yang dimiliki baik bagian 
pentransfer panas maupun penerima panas, dengan exergi yang berlimpah dan selisih yang relatif kecil, hal ini menjadikan tipe ini memiliki daya output yang paling besar diantara tipe lain, ketepatan memilih titik yang memiliki mass flow yang paling besar sesaat sebelum memasuki turbin membuat wadah penerima panas menjadi semakin besar dan menerima panas yang besar sehingga dapat memutarkan turbin secara maksismal.

Gambar 5 merupakan grafik antara exergi terhadap temperatur reservoir untuk setiap jenis pembangkit, dapat terlihat bahwa mixture heating memilki exergi yang paling tinggi diantara yang lain dengan kenaikan exergi rata rata $1.1 \%$, diikuti oleh reheating dengan keinakan exergi rata-rata $0.1 \%$ dan superheating dengan penurunan exergi rata rata sebesar $11.8 \%$ jika dibandingkan dengan double flash, grafik diatas memiliki urutan yang sama dengan urutan grafik daya output terhadap temperatur, hal ini merepresentasikan bahwa exergi yang dimiliki oleh pembangkit sejalan dengan daya output,namun jika dilihat lebih seksama, dapat terllihat bahwa selisih antara tipe reheating dengan double flash sangat kecil dan hampir sama, ini berarti kemampuan untuk melakukan kerjanya relatif sama, namun jika dilihat selisih daya outputnya relatif significant, artinya kemampuan tipe reheating untuk mengkonversi exergi atau kemampuan pembangkit melakukan kerja menjadi real kerja lebih baik dibanding double flash. Pada gambar ini juga terlihat bahwa tipe superheating memang memiliki exergi yang dibawah diantara jenis lainnya sehingga tidak heran daya output tipe ini paling sedikit diantara yang lainnya.

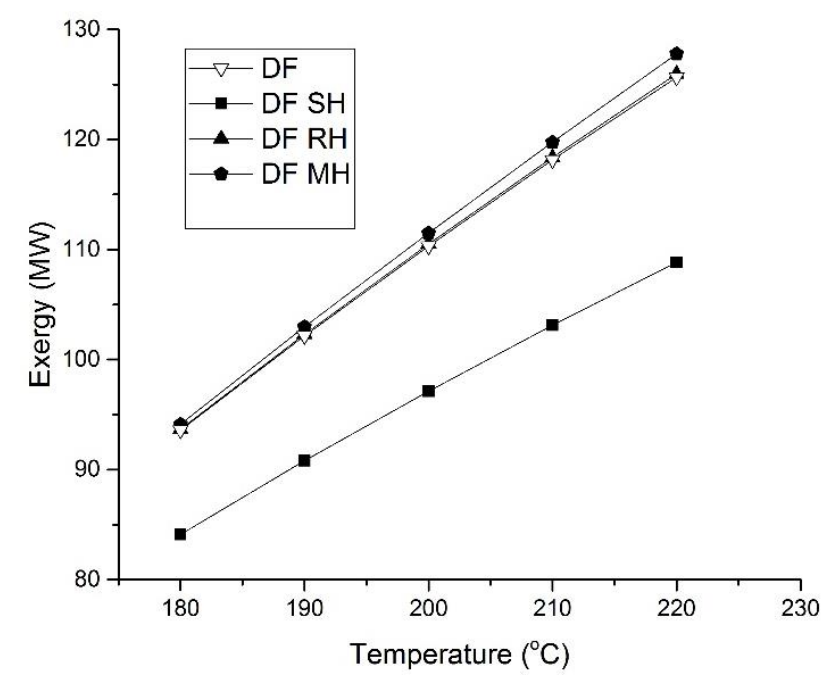

Gambar 5 . Grafik perbandingan exergi terhadap temperatur reservoir

\section{Kesimpulan}

Penelitian ini telah dilakukan dengan cara menganalisis secara termodinamika dan exergi untuk model pembangkit double flash dan double flash yang menggunakan interstage heating (Superheating, Reheating dan Mixture-heating). Hasil analisis mengatakan atau merepresentasikan bahwa interstage heating dapat menjadi konsep yang positif atau negative karena dapat menaikan atau menurunkan nilai daya output, tipe yang dapat menaikan daya output adalah mixture heating dan reheating, sedangkan tipe yang dapat menurunkan daya output adalah superheating. 
Analisis dilakukan dengan cara melihat distribusi exergi di heat exchanger, penempatan titik penerima panas menjadi suatu hal yang krusial karena harus dilakukan pada titik yang tepat, agar proses pemanfaataan panas pembangkit secara optimal terjadi dan bukan menambah kuantitas dari panas yang terbuang. Konsep interstage heating ini merupakan konsep yang bagus karena dapat mengoptimalkan pembangkit dengan cara memanfaatkan panas internal agar daya ouput meningkat, namun yang perlu jadi penelitian lebih lanjut adalah nilai ekonomi dari sistem ini karena akan ada penambahan komponen tambahan yaitu heat exchanger. Namun secara keseluruhan intinya konsep ini dapat mengoptimalkan pembangkit double flash,tipe yang paling optimal adalah mixture heating dengan terjadinya kenaikan daya output rata-rata sebesar 7,6\% dan exergi rata-rata sebesar $1.1 \%$.

\section{Ucapan Terima Kasih}

Penulis ingin mengucapkan terima kasih kepada program Academic Leadship Grant (ALG), Rektor Universitas Padjadjaran nomor kontrak 3377/UN6.D/LT/2019 yang sudah mendanai penelitian ini.

\section{DaftarPustaka}

1. Pambudi, Nugroho Agung. Geothermal power generation in Indonesia, a country within the ring of fire:Current status, future development and policy. Renewable and Sustainable Energi Reviews (2017), http://dx.doi.org/10.1016/j.rser.2017.06.096.

2. KEMENTERIAN ENERGI DAN SUMBER DAYA MINERAL. 2018. Ini Dia Sebaran Pembangkit Listrik Panas Bumi di Indonesia. https://www.esdm.go.id/id/media-center/arsip-berita/ini-dia-sebaranpembangkit-listrik-panas-bumi-di-indonesia (Diakses 17 January 2020).

3. Saptadji, Nenny. 2005. Energi Panas Bumi (Geothermal Energi). Bandung : ITB.http://geothermal.itb.ac.id/sites/default/files/public/Sekilas_tentang_Pana s_Bumi.pdf.

4. Permana, Moch. Aril I, Naufal N, Ahmad Q.A.H, Mutiara N, Cukup Mulyana . Kajian Potensi Silica Scaling Pada Pipa Produksi Pembangkit Listrik Tenaga Panas Bumi (Geothermal). Jurnal Material dan Energi Indonesia Vol. 07, No. 01 (2017) $38-43$.

5. M. El Haj Assad, E. Bani-Hani and M. Khalil. 2017. Performance of geothermal power plants (single, dual, and binary) to compensate for LHCCERN power consumption: comparative study. Geothermal EnergiScience Society - Technology (2017) https://doi.org/10.1186/s40517-017-0074-z.

6. R. DiPippo. 2008. Geothermal Power Plants : principles, applications, case studies and environmental impact. 2nd ed.Walthan. MA, USA: Elsevier, Ltd.

7. Joachim-André Raymond Sarr, Franc, ois Mathieu-Potvin. 2015. Improvement of Double-Flash geothermal power plant design: A comparison of six interstage heating processes. Geothermics 54 (2015) 82-95 doi:10.1016/j.geothermics.2014.12.002.

8. F. Mathieu-Potvin. Self-superheating: a new paradigm for geothermal powerplant design. Geothermics 48 (2013), 16-30. 
9. R. DiPippo. Geothermal Double-Flash plant with interstage reheating: anupdated and expanded thermal and exergetic analysis and optimization. Geothermics 48 (2013), 121-131.

10. Pambudi, Nugroho Agung, Ryuichi Itoi B, Saeid Jalilinasrabady, Khasani Jaelani. Performance improvement of a single-flash geothermal power plant in Dieng, Indonesia, upon conversion to a double-flash system using thermodynamic analysis. Renewable Energy 80 (2015) 424-431. http://dx.doi.org/10.1016/j.renene.2015.02.025.

11. S.E. Jørgensen SE, H. Mejer. Ecological buffer capacity. Ecol Model 1977;3:39e45. 47,49,51,53-61 